\title{
HARMONIZED AND SYSTEMATIC ASSESSMENT OF MICROALGAE ENERGY POTENTIAL FOR BIODIESEL PRODUCTION
}

\section{Francesco Arcigni ${ }^{1}$, Riccardo Friso ${ }^{1}$, Maurizio Collu ${ }^{2}$, Mauro Venturini ${ }^{1}$ *}

${ }^{1}$ Dipartimento di Ingegneria, Università degli Studi di Ferrara, Via Giuseppe Saragat, 1, 44122 - Ferrara (Italy)

${ }^{2}$ Department of Naval Architecture, Ocean \& Marine Engineering, University of Strathclyde, 100 Montrose Street, Glasgow G4 OLZ, United Kingdom

${ }^{*}$ Corresponding author: Mauro Venturini

Dipartimento di Ingegneria - Università degli Studi di Ferrara

Via Giuseppe Saragat, 1, 44122 - Ferrara (Italy)

Phone\#: +390532974878

email address: mauro.venturini@unife.it 


\section{ABSTRACT}

With their fast growth rate and ability to accumulate a high percentage of their weight as lipid and carbohydrate, microalgae potentially represent an ideal feedstock for the production of biodiesel and bioethanol. In addition, microalgae offer several environmental benefits, and do not compete with food production for land, fresh water, and nutrients.

Therefore, the main goal of this work is to provide a quantitative, systematic and harmonized assessment of current bio-energy potential. The analysis is conducted by considering all the main steps in detail, from cultivation to biodiesel production, and by deriving an overall estimation of energy consumption for biodiesel production. Energy consumption uncertainty is also quantified and discussed. A systematic review of all the main technologies available for all the main processing steps towards the production of biodiesel from microalgae is presented, focusing on the derivation of the Net Energy Ratio (NER) of each combination of technologies, complemented by an uncertainty analysis of the data used and those obtained in the present work.

A wide scatter in the data available in the literature has been identified, highlighting the need for an uncertainty analysis. If the average overall energy consumption per unit of biodiesel mass is considered, all the routes adopting a raceway pond have a lower energy consumption, but if the uncertainty on the overall energy consumption is also considered, the minimum value of the range of NER values for some of the routes adopting a photobioreactor is comparable to the NER value obtainable by using raceway ponds.

Thus, the present framework proposes a harmonized and comprehensive methodology to compare and contrast technologies for the production of biodiesel from microalgae, and is applied in this paper to identify, with an appreciation of the uncertainty, the most promising combinations of technologies.

Keywords: microalgae; bioenergy; biodiesel; net energy ratio; uncertainty.

\section{NOMENCLATURE}

\section{E $\quad$ Energy $[\mathrm{MJ}]$}

LHV Lower Heating Value $[\mathrm{MJ} / \mathrm{kg}]$

$m \quad$ Mass $[\mathrm{kg}]$

$M \quad$ Ratio of output mass to input mass $m_{\mathrm{o}} / m_{\mathrm{i}}[-]$

NER Net Energy Ratio [-]

\section{$\underline{\text { Subscripts and Superscripts }}$}


$1,2,3,4 \quad$ process $1,2,3,4$

$\begin{array}{ll}\text { al } & \text { algae } \\ \text { BD } & \text { biodiesel } \\ \text { bo } & \text { bio-oil } \\ \mathrm{db} & \text { dry biomass } \\ \mathrm{i} & \text { input } \\ \mathrm{m} & \text { mean value } \\ \text { o } & \text { output } \\ \text { ov } & \text { overall } \\ \text { sd } & \text { standard deviation } \\ \text { wb } & \text { wet biomass }\end{array}$

\section{$\underline{\text { Acronyms }}$}

DR Dryer

F\&C Flocculation and centrifuge

HEX Hexane extraction

HOM Homogenization

HT Hydrotreatment

HTL Hydrothermal

PY Pyrolysis

PBR Photobioreactor

RP Raceway pond

SCW Subcritical $\mathrm{H}_{2} \mathrm{O}$

SD Solar drying

TE Transesterification 


\section{INTRODUCTION AND PROBLEM STATEMENT}

The global energy demand has been continuously increasing over the past decades, and is also projected to increase, due both to the population growth and to the demand for higher living standards [1]. This is true even if considering that the energy intensity (expressed as energy per gross domestic product unit) and the carbon intensity (in terms of $\mathrm{CO}_{2}$ per energy unit) have been decreasing over the past decades, and are projected to decrease even more over the next three decades [2]. Approximately $25 \%$ of world energy consumption is due to the transportation of people and goods, the majority of this being used for passenger transportation, in particular light-duty vehicles [2]. Moreover, approximately $20 \%$ of the global $\mathrm{CO}_{2}$ emissions are due to the transport sector, and these are forecasted not to substantially diminish over the coming decades, since the number of light motor vehicles is estimated to increase to over 2 billion by 2050 [3].

There is therefore an urgent need for a substantial displacement of fossil fuel use, to tackle both the present and future energy and emissions challenges. Biofuels, produced from biomass rather than fossil oil, are considered part of the solution to tackle these challenges. There are solid (bio-char), liquid (ethanol, vegetable oil, and biodiesel), and gaseous (biogas, biosyngas and biohydrogen) fuels, and they are usually classified based on the type of feedstock used. The first-generation liquid biofuels are produced using edible feedstock such as corn, soybean, sugarcane, and rapeseed. Therefore, they directly compete with food production. Since food production is another of the most urgent challenges [4], a second-generation of biofuels has been developed, which uses non-edible feedstock such as Jatropha, Miscanthus, and Switch grass and also exploits crop residues [5]. Nonetheless, non-edible feedstock still competes with food production, due to the need for arable land, fresh water, and nutrients for their cultivation. Two recent joint studies have proposed a comprehensive modelling framework capable of disclosing the nexus among energy, economy, land use and GHG emissions in case of bioenergy exploitation [6], by also focusing on the effect of an accelerated deployment of bioenergy on land use [7].

For these reasons, a third and fourth generation of biofuels have been introduced, respectively using microalgae and macroalgae (third generation) and metabolic engineering of photosynthetic organisms to produce biofuels (fourth generation) [8].

Microalgae have received considerable attention in recent years, because their fast growth rate and potential to accumulate a high percentage of their weight as lipid and carbohydrate make them an ideal feedstock for the production of biodiesel and bioethanol. Moreover, $\mathrm{CO}_{2}$ sequestration, self-purification, and effective land utilization are some of the environmental benefits offered by microalgae, which do not compete with food production for land, fresh water, and nutrients.

As for other forms of renewable energy, the interest in the use of microalgae as an alternative source of fuel for transportation was born as a result of the oil embargo of 1973, and since then it has been considered as part of the solution to tackle the energy and emission challenges in the U.S. $[9,10]$, but also in other countries [11]. In 1978, a major research programme was initiated in the U.S. (Aquatic 
Species Program), focusing on the use of microalgae as a source of biodiesel [9], concluding that no major technical barriers are present, but the high cost of production remains the main challenge. From the point of view of environmental impact, Lapinskiene et al. [12] demonstrated that diesel fuel (derived from fossil oil) is toxic to soil microorganisms at concentrations higher than $3 \%$ (w/w), while biodiesel is non-toxic even at $100 \%$ soil saturation. Furthermore, using biodiesel has a net zero impact on the amount of $\mathrm{CO}_{2}$ and $\mathrm{SO}_{\mathrm{x}}$, and is in general less polluting than petro-diesel [13 - 15].

Therefore, in order to support the development of large-scale biodiesel production plants, able to displace the use of a substantial amount of fossil fuel, it is essential to investigate which, among all the main technologies available for all the processing steps (from microalgae cultivation to biodiesel production), are the most suitable. In the present work, the criterion to assess the suitability of a solution is based on the index called the Net Energy Ratio (NER), i.e. the ratio between the output energy content and the energy required to produce that output.

Unfortunately, in the current literature, two major challenges are present: (1) a lack of reviews covering, in a coherent manner, all the main available technologies for all the main processing steps towards biodiesel production, and (2) a substantial scatter among the available published data, even for the same processing step and the same technology. With regard to the first challenge, data may be available for all the main processing steps (cultivation, harvesting, oil extraction, biodiesel production), but only for some of the possible available technologies. On the other hand, data may be available for a wide range of possible technologies, but in most cases they focus only on some of the processing steps.

In the present work, the authors' main aim is to present a systematic review of all the main technologies available for all the main processing steps towards the production of biodiesel from microalgae, focusing on the derivation of the NER of each combination of considered technologies, to quantitatively compare them and identify the most promising ones. Of equal importance, an additional novel contribution to knowledge is the uncertainty analysis of the data used for each technology of each processing step, which is then considered to also derive the uncertainty on the final results (NER): a low performance level may be an indicator of the unsuitability of such technology, while a high performance level coupled with a high uncertainty on this performance may suggest the need for further research on this technology.

\section{TECHNOLOGIES}

In the following, a brief description of all the main technologies available in the literature is documented, by citing relevant sources for a more in-depth analysis. It should be noted that some of the available technologies have not been considered, for two main reasons: 
there were extremely few data available about that technology and/or the level of reliability of the data found for those technologies was deemed to be very low. The technologies considered in the following are classified as shown in Table 1.

\section{$\underline{2.1 \text { Raceway pond }(R P)}$}

A promising microalgae cultivation system is the raceway pond technology, which consists of an open-air container in which the culture blend is kept in motion by paddlewheels, which also provide the necessary mixing turbulence. Nutrients have to be injected periodically, together with the correct amount of $\mathrm{CO}_{2}$, due to the continuous evaporation. Therefore, water has also to be regularly pumped into the system to maintain a constant level, around $30 \mathrm{~cm}$ [16]; this is an optimal value that represents a compromise between the amount of sunlight penetrating through the whole culture depth and the extent of the pond, but is limited by economic considerations.

Evaporation, culture contamination by external organisms, and the lack of control over the environmental conditions (weather conditions) have pushed some researchers to propose a closed raceway pond system, but to date its economic feasibility is still in question [17].

The energy required by an RP is mainly necessary to power the paddlewheels mixing the culture; a compromise between culture productivity and energy consumption (increasing cubically with respect to algal mass circulating speed) suggests an optimum trade-off value for the velocity of the raceway of around $0.3 \mathrm{~m} / \mathrm{s}$ [18]. Even if characterized by a relatively low algal productivity/surface ratio, the simple and cheap design of the pond, as well as its low maintenance costs, make it a promising solution for large scale production plants.

\section{$\underline{2.2 \text { Photobioreactor (PBR) }}$}

Photobioreactors are essentially closed, transparent cultivation systems, where nutrients are injected in order to maintain the optimal conditions, guaranteeing the highest possible growth rate. Nutrient requirement is known to depend on the species but also on the desired level of stress to stimulate lipid or carbohydrate storage. Geider and La Roche [33] state that the nitrogen and phosphorous ratio strongly varies during a starvation period. The effectiveness of using fertilizers varies according to both the considered species, even though it can also vary for a given species of microalgae [26].

Photobioreactors present different configurations, with the common aim being to maximize both the area/volume ratio and the area exposed to direct light. The most common configurations are the closed-loop tubular PBRs, installed horizontally, and the vertical PBRs with flat plates, as well as the airlift columns. Both vertical and horizontal tubular PBRs are widely used in conjunction with a degassing unit and $\mathrm{CO}_{2}$ to achieve higher biomass productivity [19]. Various authors state that the horizontal configuration can reach higher production rates, due to its larger surface/volume ratio [19]. 
While, compared to raceway ponds, PBRs present a sensibly higher biomass productivity, mainly due to the ability to control the growing conditions, the significant capital costs of the structure and supporting systems constitute the main challenge to the development of this cultivation technology on a large scale. The flat plate and airlift column PBRs appear to be a possible solution; since they are made from thin plastic material, the capital costs are considerably reduced [19].

\section{$\underline{2.3 \text { Flocculation and centrifuge }(F \& C)}$}

The flocculation step consists of the addition of "flocculant agents" to concentrate the algal mass by the aggregation of microalgae cells. This is necessary to perform an efficient centrifugation step, as the last operation of the harvesting process.

Today, two main flocculation processes are used, depending on the type of flocculant: additive flocculation or bio-flocculation (often called auto-flocculation). The second technique is highly suitable for aquaculture applications due to its chemical-free nature [20]; with the same efficiency as the chemical processes, bio-flocculation can concentrate the biomass from $0.5 \mathrm{~g} / 1$ (average culture algal concentration) to $10 \mathrm{~g} / 1[21]$.

The aim of the centrifugation step is to remove vast amounts of water quickly and efficiently, but is linked to high energy costs. By exploiting the centrifugal force, water is separated from the biomass; depending on the size and configuration of the device, energy consumption can vary substantially.

A widely used configuration is the decanter centrifuge, which is based on the concept of using a special settling tank in which the solids in suspension are forced to sink due to the gravitational forces. The decanter centrifuge operates continuously by pumping the cultivated microalgae biomass into the centrifuge bowl whereby the suspended particles in solution are forced to the bottom of the bowl [34]. The deposition enhances the solid-liquid separation, reaching a $180 \mathrm{~g} / \mathrm{l}$ concentration [21].

\section{$\underline{2.4 \text { Homogenization (HOM) }}$}

The wet extraction process requires a disruption of the cells' membrane. Only the homogenization technique has been considered in this work, due to its predominance in the literature, and being a common previous step to the considered wet extraction techniques. This cell disruption technique utilizes a pressure variation, due to passing from a wider to a narrower duct, and the friction caused by the speed [22].

Several studies indicate homogenization as one of the most efficient methods, capable of achieving levels of up to $70 \%$ disrupted cells fraction [23]; the process produces only a small amount of heat (i.e. does not require a cooling system), and it also seems economically suitable to be adopted for high productivity. However, despite its advantages, a long time, and thus a considerable amount of energy, is required to complete the disruption process [23]. Sheng et al. [35] state that homogenization leads to optimal cell disruption. 
Halim et al. [36] compared the efficiency of the principal processes and report that a higher efficiency of homogenization was observed with higher pressure (500-800 bar) and cell concentration.

\subsection{Hydrothermal liquefaction (HTL)}

The hydrothermal liquefaction extraction technique consists of processing the biomass using a hot compressed solution, subsequently liquefied into bio-oil, aqueous solution gas, and a minor solid part [24]. The by-products can be recycled: the aqueous solution is full of nutrients, the gas produced during the process is mainly composed of $\mathrm{CO}_{2}$ and $\mathrm{H}_{2}$, both recyclable, and the solid part can be utilized as a co-product.

Good efficiency has been proved in converting wet biomass with $20 \%$ of solid fraction [25]. Therefore, HTL is suitable for wet extraction. Temperature and pressure of the process have to be controlled $\left(200{ }^{\circ} \mathrm{C}-350{ }^{\circ} \mathrm{C}\right.$ and $\left.10 \mathrm{MPa}-25 \mathrm{MPa}\right)$ in order to maintain the water in the sub-critical region [26]. In those conditions, molecules are disrupted and re-polymerized into oily molecules.

An additional step is however required at the end of the process: nitrogen and oxygen, generated in high concentrations, have to be removed before further processing the bio-oil [24]. Some researchers argue that the presence of $\mathrm{NO}_{\mathrm{x}}$ in flue gases poses little or no problem to microalgal growth. In fact, a few tolerant microalgae exist, capable of growing at $\mathrm{NO}_{\mathrm{x}}$ concentrations of up to $300 \mathrm{ppm}$ [37]. Instead, the review conducted by Yen et al. [38] points out that $\mathrm{NO}_{\mathrm{x}}$ can be even utilized as a nitrogen source to promote microalgal growth when it dissolves and is oxidized in the culture medium. For these reasons, reducing $\mathrm{NO}_{\mathrm{x}}$ emissions coming from HTL is currently an active area of research.

\section{$\underline{2.6 \text { Hexane extraction (HEX) }}$}

This is a method that belongs to the general category of solvent extraction. The extraction mechanism is based on the higher solubility of lipids into the chemical solvent (once properly mixed into the solution), then separated from the algal cells. The purpose of this process is to guarantee an adequate recovery of Triacylglycerols.

Different types of solvent have been evaluated in the literature, reaching high efficiencies with methanol and chloroform used together (nearly 99\% [27]). However, the literature review has highlighted that hexane is the most commonly adopted and quantitatively assessed solvent to treat algal biomass; as the most mature method, the authors have decided to adopt it for the energy analysis.

The main challenges with this type of extraction are (i) the need for a preliminary effective cell disruption or drying step in order to perform an efficient extraction process and (ii) the necessary successive separation to isolate the algal lipids.

\section{$\underline{\left.2.7 \mathrm{H}_{2} \mathrm{O} \text { sub-critical extraction ( } \mathrm{SCW}\right)}$}


The principle used for this technique is the hot water tendency to become an organic solvent for the oily fraction of the biomass, in such a manner that it separates it from the solution. It has been demonstrated [28] that water can be used to break cell bonds and separate oil, at a temperature not much higher than boiling point, with a moderate pressure [29] (i.e. slightly below the critical conditions).

One option is represented by the possibility of collecting the water extracted from the previous harvesting step to perform the SCW; this also allows low solid fractions in the algal biomass (below 10\%). Consequently, low harvesting energy demand due to the low solid mass required, and recycling material from other steps, enhance the economic viability and the low energy demand of this extraction technique.

Efficiency data (up to 70\% [28]) have been collected mainly from small-scale experiments; therefore, the performance of this method when processing higher yield amounts is not established.

\section{$\underline{2.8 \operatorname{Dryer}(D R)}$}

In this work, the authors consider a dryer which exploits either a mechanical or thermal process, even though the dry weight achieved for the two techniques is different. A drying process is necessary for pyrolysis, while it is useful (but not mandatory) for hexane extraction. The purpose is generally to increase the solid content of the harvested algae to at least $80 \%$ [21].

In addition to the achieved dry weight, mechanical and thermal processes have different energy consumption. However, this difference is not taken into account in this paper when considering the best/worst case in order to estimate an average value of the energy demand.

\section{$\underline{2.9}$ Solar drying $(S D)$}

The algal paste usually requires two-thirds of the heating energy necessary for drying the whole algal biomass [30]. Therefore, algaedrying by using fossil fuels may lead to a negative energy balance. Thus, in recent years, solar drying has been suggested as a possible way to reduce the amount of energy used.

In this paper, solar drying is considered for its renewability and zero-energy requirement. The two main drawbacks of this process are that it is climate dependent, and requires a longer time than other drying techniques. Another drawback of solar drying is the required surface area. Even though there is a lack of data in the literature about this type of drying process, Abu-Ghosh et al. [30] estimate an area of approximately $11 \mathrm{~m}^{2}$ for producing $1 \mathrm{~kg}$ of biodiesel. Such a value is very large compared to the compactness of industrial dryers and may be a barrier to industrial applicability.

\section{$\underline{2.10 \text { Pyrolysis (PYR) }}$}

Pyrolysis is a physical-chemical process in which biomass is heated to between $400{ }^{\circ} \mathrm{C}$ and $800{ }^{\circ} \mathrm{C}$, resulting in the production of a solid phase rich in carbon and a volatile phase composed of gases and condensable organic vapours. These organic vapours condensate 
in two different phases: bio-oil and acid extract. Due to the temperature and heating rates at which biomass is submitted, many simultaneous reactions occur, resulting in gaseous, liquid and solid products [26].

In this paper, fast pyrolysis is considered. Fast pyrolysis is a fast thermal degradation process: biomass is rapidly (in the order of seconds) heated and subsequently rapidly cooled in the absence of oxygen. Process outputs are mostly vapours, aerosols and charcoal (char). After condensation, a liquid pyrolysis bio-oil is also produced. The liquid yield can be improved by increasing the heating rate (up to $10^{4} \mathrm{~K} / \mathrm{s}$, according to [39]), at reaction temperatures of approximately $500{ }^{\circ} \mathrm{C}$; short vapour residence times are also helpful for minimizing secondary cracking of the primary products [31].

\section{$\underline{2.11 \text { Transesterification (TE) }}$}

The transesterification process comprises the reaction of triglycerides with alcohol in the presence of a catalyst, to produce glycerol and mono-alkyl fatty acid esters. Biodiesel is usually transesterified by using methanol, to eventually produce fatty acid methyl esters [26]. As in [32], the energy demand for algal oil transesterification is assumed to be similar to that required for soybean oil transesterification.

\section{$\underline{2.12 \text { Hydrotreatment (HT) }}$}

The bio-oil produced can be converted to biodiesel through hydroprocessing, which uses hydrogen to remove the excess nitrogen and oxygen from the bio-oil. The hydrogen needed for hydroprocessing depends on the bio-oil composition [25].

\section{METHODOLOGY}

On the basis of the literature survey and the challenges discussed above, the complete chain from algae to biodiesel, considered in this paper, is sketched in Figure 1. It is split into four main steps:

1. Cultivation, which can be carried out using raceway ponds (RP) or photobioreactors (PBR). The output of this process is "wet biomass".

2. Harvesting, involving the flocculation and centrifuge techniques $(\mathrm{F} \& \mathrm{C})$. The output is dry biomass.

3. Extraction, which can be split into two main paths, i.e. "wet path" and "dry path", which in turn can be split into three (HOM+HTL, $\mathrm{HOM}+\mathrm{HEX}, \mathrm{HOM}+\mathrm{SCW}$ ) or four (DR+PY, DR+HEX, SD+PY, SD+HEX) sub-paths, respectively. It should be noted all the wet sub-paths also include a homogenization pre-processing. Instead, two dry paths consider the use of a dryer (which is very energyconsuming), while the remaining two dry paths make use of solar drying. Moreover, hexane extraction can be performed both in the wet and dry paths. After this step, bio-oil is available.

4. Biodiesel production, which can be made by using the classic process of transesterification (TE) or the less consolidated process 
of hydrotreatment (HT). The final product is biodiesel.

It is worth highlighting that:

- the use of sedimentation and centrifuge for harvesting is not considered in this paper, since, though less energy intensive, the coagulation methods could negatively affect the biomass quality [40]. As an example, data collected on lab-scale photobioreactors showed that a harvesting efficiency of $65 \%$ is required to pump $76,923 \mathrm{~m}^{3} /$ day for an installation of 100 ha, with an electric energy consumption of $3825 \mathrm{kWh} /$ day [41];

- dryer energy consumption is averaged over both thermal and mechanical dryer data. In this manner, dryer energy consumption is representative of both worst (i.e. thermal dryer) and best (i.e. mechanical dryer) scenarios;

- solar drying is also considered in this paper for extraction since, as discussed in [42], using natural gas as the fuel for drying microalgae biomass consumes nearly $69 \%$ of the overall energy input and may lead to a negative energy balance in producing microalgae biofuels. On the other hand, solar drying clearly requires a longer time. For instance, one study [30] documents that every ton of dry biomass produced from drying a 5000 -litre culture (20\% solids), on a surface of $1000 \mathrm{~m}^{2}$ and with a 5 cm culture depth, required (on average) 2-2.5 sunny days.

\subsection{Data}

The quantitative assessment of the energy potential of biodiesel is based on literature data. Some of the data are taken directly from the sources, while the majority are derived by processing the data in the sources, in order to harmonize them. In fact, one of the major achievements of this paper is the definition of a specific energy value for each step of the chain, to be used for all the possible routes. In order to estimate the specific energy required for each step, mass ratio values, derived from the cited papers, are used. Mass ratios were reported as mass growth (in the case of the cultivation process) or mass loss (for the remaining processes).

Table 2 documents the data values and respective sources, and step-by-step data homogenization. The following observations can be made:

- the different papers only consider some of the steps of the complete chain. On the basis of the literature survey, there are only a few papers which analyze the whole chain;

- the values labelled as "original value reported in the source paper" in Table 2 are often the result of a preliminary processing made by the authors of this paper, to refer those values to the input mass of each process;

- the values labelled as "assumption" in Table 2 are equal to the average values of the known processes or taken from other papers. This applies to the cases in which some data were not explicitly reported or mentioned in a paper.

- for a given process and a given source (e.g. paper [51] for HEX), the specific energy values (referred to as process input mass 
- see bold values in Table 2) are considerably scattered. Moreover, given the different number of available sources, the statistical meaningfulness of the homogenized values is also variable. For both reasons, a specific analysis about uncertainty will be carried out in the present work.

\subsection{Uncertainty}

Uncertainty can be defined as a lack of knowledge or limited information about a present state or a future event. According to [58], two types of uncertainties, both applicable to bioenergy systems, can be identified: epistemic uncertainty, which is the systematic uncertainty based on imprecise, unavailable or even unmeasurable knowledge and data, and aleatoric uncertainty, which refers to the statistical uncertainty describing variations in single values and is therefore measurable.

Policy makers often face challenges concerning the reliable estimation of resource availability and recoverability, for both fossil fuels $[59,60]$ and bioenergy [61]. Another area of uncertainty is related to public attitudes and acceptability [62]. A further uncertainty is related to life cycle emissions for future bioenergy deployment, mainly due to up-front greenhouse-gas emissions from both direct and indirect land-use change [63]. Uncertainty is also related to cost estimation. For example, the estimation of the cost of production of fuel from microalgae may vary because of different economic input assumptions, different growth phase input assumptions, and different technology selections for growth [24].

To tackle this issue, various studies have proposed a number of frameworks and structures to categorize the multiple types of uncertainties related to modelling biomass production and exploitation, and different approaches are adopted to deal with the uncertainty estimation of energy chains.

Spiegelhalter and Riesch [64] proposed a five-level structure for uncertainty associated with mathematical models in general. The considered uncertainties are associated with the unavoidable unpredictability of future events, limited information of model parameters and limited knowledge about model structure.

Another approach to address uncertainty in estimating biomass energy potential is a boundary analysis, which produces limits on the potential by defining minimum, maximum and most likely values for parameters [65].

Malca and Freire [66] evaluated the implications of uncertainty in the life cycle energy efficiency and greenhouse gas emissions of rapeseed oil. Uncertainties included both parameter and scenario uncertainty, also uncertainty due to modelling choices.

Gonzalez-Salazar et al. [67] presented a methodology to estimate biomass energy potential and its associated uncertainty at a country level when quality and availability of data are limited. Uncertainty was estimated by combining a probabilistic propagation of uncertainty, a sensitivity analysis and a set of disaggregated sub-models. Some of those authors also improved the prediction reliability in [68] by using a robust selection of probability density functions and a sensitivity analysis to identify key variables contributing to 
uncertainty.

For the specific case of algae, one study [69] compared different processes of algal biofuels production on an experimental basis. Results showed statistically significant differences in algal biomass composition, due to different measurement chemistries. Instead, another study [31] carried out a life cycle assessment to investigate the impacts of combining different algae cultivation techniques and fuel conversion pathways on greenhouse gas emissions and life cycle fossil energy demand.

In this paper, to assess the uncertainty affecting the energy potential estimates used, a relatively simple and straightforward approach, based on the standard deviation, is adopted, which can be justified as follows.

A substantial source of uncertainty is the lack of a harmonized approach when considering a wide range of biodiesel production techniques, and assessing and reporting the key variables used to perform an energy potential analysis, such as the present one. Moreover, in other cases, some intermediate values (e.g. input/output mass ratios), necessary for the analyses conducted in this paper, are not reported and therefore, to be on the safe side, they are assumed to be equal to the average values of the known parameters taken from other sources. Furthermore, and most importantly, the data scatter among the different sources is significant, as demonstrated by the fact that the standard deviation of some quantities is comparable to, or even higher than, the respective mean value. In fact, the considered literature sources are characterized by different assumptions about the energy consumption of the considered process. Even if the conversion technology considered is the same, no detailed specifications are usually reported in the source papers, so that direct comparison is not straightforward.

Based on these considerations, it has been deemed more appropriate to adopt a well-known, transparent, robust, and flexible approach, such as the one based on standard deviation, to be used as an upper/lower bound to be added to the base case, as made for example in [65]. More advanced uncertainty assessment techniques would be more appropriate when analysing a specific group of biodiesel production techniques, for which the data are provided in a more consistent way, therefore reducing the input data scatter of the uncertainty analysis.

\subsection{Estimation of energy demand and mass ratio}

On the basis of the data reported in Table 2, each process (and sub-process) can be characterized by the energy demand per unit of input mass, and the corresponding mass ratio. However, since data values are usually scattered over a relatively large range, the mean value and standard deviation are adopted. The harmonized values of the data in Table 2 are reported in Table 3. It can be observed that, in the cultivation process, the energy consumption of PBR is approximately 50 times that of RP, and the mass ratio is four times that of RP. In general, data scatter is significant, since in many cases the magnitude of the standard deviation is comparable to the respective mean value and, in the case of both $M$ and $E$ of PBR, it is even larger. 
The scatter of the data reported in Table 2 is highlighted in Figures 2 and 3 for mass ratio and energy consumption, respectively. For the sake of comparison, the nondimensional values in Figures 2 and 3 were calculated by dividing each value reported in Table 2 by the respective mean value reported in Table 3. In this manner, the scatter of both mass ratio and energy ratio can be evaluated separately.

Figure 2 shows that the scatter of the mass ratio is (i) quite similar for the different processes, and (ii) smaller only in a few cases (e.g. HOM, TE, HT). Instead, Figure 3 shows that scatter of energy consumption data is more process-dependent, and is usually much higher.

\subsection{Estimation of energy consumption and Net Energy Ratio}

The overall energy consumption per unit of mass of produced biodiesel $\left(E_{\mathrm{ov}} / m_{\mathrm{BD}}\right)$ can be calculated according to Eq. (1):

$\frac{E_{\mathrm{ov}}}{m_{\mathrm{BD}}}=\frac{1}{M_{1} M_{2} M_{3} M_{4}} \frac{E_{1}}{m_{\mathrm{al}}}+\frac{1}{M_{2} M_{3} M_{4}} \frac{E_{2}}{m_{\mathrm{wb}}}+\frac{1}{M_{3} M_{4}} \frac{E_{3}}{m_{\mathrm{db}}}+\frac{1}{M_{4}} \frac{E_{4}}{m_{\mathrm{bo}}}$

thanks to the definition of step-by-step mass ratios $\left(M_{1}=m_{\mathrm{wb}} / m_{\mathrm{al}} ; M_{2}=m_{\mathrm{db}} / m_{\mathrm{wb}} ; M_{3}=m_{\mathrm{bo}} / m_{\mathrm{db}} ; M_{4}=m_{\mathrm{BD}} / m_{\mathrm{bo}}\right)$ and energy demand $\left(E_{1} ; E_{2}\right.$; $\left.E_{3} ; E_{4}\right)$. In this paper, because of the significant variability of data, the overall energy consumption per unit of mass of produced biodiesel is estimated by considering the mean values of energy demand and mass ratio reported in Table 3.

To assess the potential of each route, the NER index, defined in Eq. (2), is adopted [25].

$N E R=\frac{L H V_{B D}}{\frac{E_{\mathrm{OV}}}{m_{\mathrm{BD}}}}$

According to Eq. (2), the NER is the ratio between the energy output of the entire chain (expressed by biodiesel LHV) and the overall specific (i.e. calculated per unit of biodiesel mass) energy consumption required to produce biodiesel.

In economics, NER is the fraction of produced energy available for net final production [70]. Thus, for a given technology, NER is a dimensionless index which can be used to quantify how "efficient" that technology is in terms of providing energy compared to the input energy required to manufacture (partly or completely) that technology. NER higher than 1 clearly implies an energy gain during the process and is clearly desired to be as high as possible. 


\section{RESULTS}

\subsection{Routes}

All the routes, resulting from all the possible combinations of the processes considered in Figure 1, are quantitatively analyzed and discussed in this paper. It has to be highlighted that hydrotreatment is coupled only with the "wet path", according to [25, 31, 32]. In fact, coupling hydrotreatment and the "wet path" improves biodiesel quality [31] and allows an improved exploitation of the hydrogen available after wet extraction [32]. Therefore, 20 routes are considered in total and are summarized in Table 4.

\subsection{Energy consumption}

The overall energy consumption per unit of mass of produced biodiesel $\left(E_{\mathrm{ov}} / m_{\mathrm{BD}}\right)$ of each route is estimated in order to provide a systematic and quantitative comparison value, to support the identification of the best route. The results are reported in Fig. 4 , by ranking the different routes in ascending order of $E_{\mathrm{ov}} / m_{\mathrm{BD}}$.

It can be observed that routes 1 to 10 (which use raceway ponds) are clearly preferable to routes 11 to 20 (which instead use photobioreactors). In fact, the overall energy consumption of routes 1 to 10 is lower than $59 \mathrm{MJ} / \mathrm{kg}$, while routes 11 to 20 require a specific energy consumption, which is considerably higher (from $120 \mathrm{MJ} / \mathrm{kg}$ for route 13 to $213 \mathrm{MJ} / \mathrm{kg}$ in the case of route 20 ). The best routes are routes $2(\mathrm{RP}+\mathrm{F} \& \mathrm{C}+(\mathrm{HOM}+\mathrm{HEX})+\mathrm{TE}), 1(\mathrm{RP}+\mathrm{F} \& \mathrm{C}+(\mathrm{HOM}+\mathrm{HTL})+\mathrm{TE})$ and $10(\mathrm{RP}+\mathrm{F} \& \mathrm{C}+(\mathrm{SD}+\mathrm{HEX})+\mathrm{TE})$ since they are all characterized by an energy consumption lower than $30 \mathrm{MJ} / \mathrm{kg}$. It is interesting to note that both routes \#2 and \#10 include the process of hexane extraction, performed in the wet (route \#2) or dry (route \#10) path.

The share of overall energy consumption by process is reported in Figure 5, where the absolute values are those reported in Figure 4. For routes 1 to 10 (RPs), the highest shares are represented by the cultivation process $(16 \%-52 \%)$ and the extraction process (30\%76\%). Harvesting accounts for 3\%-11\%, while biodiesel production accounts for 3\%-10\%. Instead, for routes 11 to 20 (which consider the use of PBRs for cultivation), the highest share is the cultivation process, which accounts for $71 \%$ - $93 \%$ of the overall energy consumption. The extraction process accounts for a maximum of $26 \%$, while the two processes of harvesting and biodiesel production together account for a maximum of $4 \%$. These values can be regarded as a guideline to identify the processes that predominantly drive the energy demand of the whole chain, and therefore are mostly worthy of further study and optimization for energy saving purposes.

\subsection{Uncertainty on energy consumption estimation}

In order to highlight how uncertainty on estimating the energy consumption of each step propagates to the overall value, all the mean values of energy consumption and mass ratio reported in Table 3 are both increased and decreased by the respective standard deviation. The considered cases are summarized in Table 5.

The results of this analysis are reported in Figure 6, where full circles refer to overall energy consumption, estimated by considering 
the mean value of energy demand and mass ratio (i.e. the same values as reported in Figure 4). When the difference between the mean value and the standard deviation is negative, the value is not reported in Figure 6.

Since in some cases the standard deviation is quite high, the order of magnitude of the energy consumption can change significantly, in such a manner that, even though routes 1 to 10 are usually preferable, routes 11 to 20 may also become feasible. Moreover, uncertainty may also make energy consumption decrease considerably.

\subsection{Net energy ratio}

To compare the different routes on the basis of the respective NER defined in Eq. (2), the values of biodiesel LHV are taken from several sources in the literature, and are listed in Table 6, together with the mean value and standard deviation. Three values of NER are evaluated in this paper for sensitivity purposes, i.e. the NER calculated by using the mean value of biodiesel LHV and those calculated by subtracting ("low" NER") or adding ("high" NER) the LHV standard deviation to its mean value. The overall specific energy consumption is estimated by considering the mean value of energy demand and mass ratio reported in Table 3 (see values reported in Figure 4).

In agreement with the results presented in Figure 4, the results presented in Figure 7 confirm that none of the routes 11 to 20 (which consider the use of PBRs for cultivation) allow NER values higher than one. The best routes are, once again, routes 2, 1 and 10, which are characterized by NER values in the range 1.65-1.95, 1.29-1.53 and 1.24-1.47, respectively. Given the uncertainty on the estimation of the overall energy consumption (see Figure 6), it is in fact advisable to target NER values at least equal to 1.5 to be on the safe side. For comparison, the current NER for conventional fossil fuel diesel is 5.6, as documented in [25].

For the purpose of comparison with the results presented in this paper, two studies document the NER values that can be achieved by considering second generation bio-fuels. Whitaker and Heath [71] found an NER of 0.79 for the biodiesel of Jatropha, which is lower than the NER of all the best routes considered in this paper, even accounting for uncertainty. Instead, Fore et al. [72] found that the NER of soybean biodiesel can reach a value of 1.78 , which is of the same order of magnitude as the best routes.

\section{CONCLUSIONS}

The global energy demand has been continuously increasing over the past decades, and is also projected to increase. A significant percentage of all the energy consumption is due to the transportation of people and goods, in particular by means of light-duty vehicles, and consequently global $\mathrm{CO}_{2}$ emissions by the transport sector are relevant. There is therefore an urgent need for a substantial displacement of fossil fuel use, to tackle both the present and future energy and emissions challenges. As a third generation biofuel, 
microalgae are a promising source of biodiesel, by not competing with food production for arable land, fresh water, or nutrients, and with no major technical barriers. Nonetheless, high production costs remain the main challenge.

The literature review has highlighted that available data suffer from two major drawbacks: (i) a lack of reviews in a coherent manner, covering all the main available technologies for all the main processing steps from cultivation to biodiesel production, and (ii) a significant scatter among the available data.

In the present work, a systematic review of all the main technologies available for all the main processing steps towards the production of biodiesel from microalgae is presented, focusing on the derivation of the Net Energy Ratio (NER) of each combination of technologies, complemented by an uncertainty analysis on the data used and those obtained through the present work.

The main results are summarised in the following points:

- a wide scatter in the data available in the literature is documented (Table 2), highlighting the need to complement the values obtained in any analysis related to biofuel production with an estimation of their uncertainty;

- 20 combinations of technologies (routes) from cultivation to biodiesel production have been considered (Table 4);

- if the average overall energy consumption per unit of biodiesel mass is considered, all the routes adopting a raceway pond for the cultivation phase have a lower energy consumption than all the routes adopting a photobioreactor (Figure 4);

- if the uncertainty on the overall energy consumption is also considered, the minimum value of the range of NER values for some of the routes adopting a photobioreactor is comparable to the NER value obtainable by using raceway ponds (Figure 6);

- for the routes which employ a raceway pond, the processing steps requiring the highest share of the overall energy consumption are the cultivation process $(16 \%-52 \%)$ and the extraction process $(30 \%-76 \%)$ (Figure 5);

- $\quad$ for the photobioreactor-based routes, the highest share is taken by the cultivation processing step, which accounts for $71 \%$ $93 \%$ of the overall energy consumption;

- $\quad$ on the basis of the estimated NER values, the best routes are routes \#2 (RP + F\&C + (HOM+HEX) + TE), \#1 (RP + F\&C + $(\mathrm{HOM}+\mathrm{HTL})+\mathrm{TE})$, and \#10 (RP + F\&C + (SD+HEX) + TE), with NER values, respectively, in the range 1.65-1.95, 1.291.53 , and 1.24-1.47.

The present work has therefore presented a systematic review and comparison of the main state-of-the-art technologies adopted for the production of biodiesel, and has highlighted which combinations of such technologies may achieve the optimum NER, with also an estimation of the relative uncertainty. The results obtained in this paper can be used as a guideline for future study and optimization of biodiesel production from microalgae with the aim of energy saving and $\mathrm{CO}_{2}$ reduction compared to fossil fuel use, mainly in the transport sector. 


\section{ACKNOWLEDGEMENTS}

The authors gratefully acknowledge Alessandro Baumgartner for his precious and kind support.

\section{REFERENCES}

[1] OECD GREEN GROWTH STUDIES: ENERGY C OECD 2011. (available at http://www.oecd.org/greengrowth/)

[2] International Energy Outlook 2017. U.S. Energy Information Administration. https://www.eia.gov/outlooks/ieo/pdf/0484(2017).pdf

[3] Balat M, Balat H. Progress in biodiesel processing. Appl Energy, 2010;87:1815-35.

[4] Godfray H C J, Beddington J R, Crute I R, Haddad L, Lawrence D, Muir J F, et al. Food security: The challenge of feeding 9 billion people, Science, 2010;327(5967):812-818.

[5] Mohr A, Raman S. Lessons from first generation biofuels and implications for the sustainability appraisal of second generation biofuels, Energy Policy 2013;63:114-122.

[6] Gonzalez-Salazar M A, Venturini M, Poganietz W R, Finkenrath M, Kirsten T, Acevedo H, Spina P R. A general modeling framework to evaluate energy, economy, land-use and GHG emissions nexus for bioenergy exploitation, Applied Energy 2016;178:223-249.

[7] Gonzalez-Salazar M A, Venturini M, Poganietz W R, Finkenrath M, Leal M R L V. Combining an accelerated deployment of bioenergy and land use strategies: Review and insights for a post-conflict scenario in Colombia, Renewable \& Sustainable Energy Reviews 2017;73:159-177.

[8] Daroch M, Geng S, Wang G, Recent advances in liquid biofuel production from algal feedstocks, Appl. Energy 102, 1371-1381.

[9] Sheehan J, Dunahay T, Benemann J, Roessler P, A Look Back at the U.S. Department of Energy's Aquatic Species Program Biodiesel from Algae, NREL/TP-580-24190, 1998.

[10] U.S.D.o. Energy, Bioenergy Technologies Office Multi-Year Program Plan, 2013. (http://www1.eere.energy.gov/bioenergy/).

[11] Global Renewable Fuels Alliance, 2017 http://globalrfa.org/biofuels-map/ (accessed on the $28^{\text {th }}$ December 2017)

[12] Lapinskiene A, Martinkus P, Rebzdaite V. Eco-toxicological studies of diesel and biodiesel fuels in aerated soil. Environ Pollut $2006 ; 142: 432-7$.

[13] Hu Q, Sommerfeld M, Jarvis E, Ghirardi M, Posewitz M, Seibert M. Microalgal triacylglycerols as feedstocks for biofuels production: perspectives and advances. Plant J 2008;54:621-39.

[14] Hulatt CJ, Thomas DN. Productivity, carbon dioxide uptake and net energy return of microalgal bubble column photobioreactors. Bioresour Technol 2011;102:5775-87. 
[15] Williams PJIB, Laurens LML. Microalgae as biodiesel \& biomass feedstocks: review \& analysis of the biochemistry, energetics \& economics. Energy Environ Sci 2010;3:554-90.

[16] Collet P, Lardon L, Helias A, Bricout S, Lombaert-Valot I, Perrier B, Lepine O, Steyer J, Bernard O. Biodiesel from microalgae Life cycle assessment and recommendations for potential improvements, Renewable Energy 2014;71:525-533.

[17] Ramos T E, Domenicali G, Bertucco A. Autotrophic production of biodiesel from microalgae: An updated process and economic analysis, Energy 2014;76:807-815.

[18] Rogers J, Rosenberg J, Guzman B, Oh V, Mimbela L, Ghassemi A, et al. A critical analysis of paddlewheel-driven raceway ponds for algal biofuel production at commercial scales, Algal Research 2014;4:76-88.

[19] Pawar S. Effectiveness mapping of open raceway pond and tubular photobioreactors for sustainable production of microalgae biofuel. Environmental Biotechnology Division, CSIR, 2016.

[20] Hamid S, Lananan F, Khatoon H, Jusoh A, Endut A. A study of coagulating protein of Moringa oleifera in microalgae bioflocculation, International Biodeterioration \& Biodegradation 2016;113:310-317.

[21] Yuan J, Kendall A, Zhang Y. Mass balance and life cycle assessment of biodiesel from microalgae incorporated with nutrient recycling options and technology uncertainties, GCB Bioenergy 2015;7:1245-1259.

[22] Samarasinghe N, Fernando S, Lacey R, Faulkner W. Algal cell rupture using high pressure homogenization as a prelude to oil extraction, Renewable Energy 2012;48:300-308.

[23] Kim J, Yoo G, Lee H, Lim J, Kim K, Kim C, et al. Methods of downstream processing for the production of biodiesel from microalgae, Biotechnology Advances 2013;31:862-876.

[24] Chaudry S, Bahri P, Moheimani N. Pathways of processing of wet microalgae for liquid fuel production: A critical review, Renewable and Sustainable Energy Reviews 2015;52:1240-1250.

[25] Bennion E, Ginosar D, Moses J, Agblevor F, Quinn J. Lifecycle assessment of microalgae to biofuel: Comparison of thermochemical processing pathways, Applied Energy 2015;154:1062-1071.

[26] Pandey A, Chisti Y, Soccol C R. Biofuels from algae, San Diego: Elsevier; 2014.

[27] Stephenson A, Kazamia E, Dennis J, Howe C, Scott S, Smith A, Life-Cycle Assessment of Potential Algal Biodiesel Production in the United Kingdom: A Comparison of Raceways and Air-Lift Tubular Bioreactors, Energy Fuels 2010;24:4062-4077.

[28] Ponnusamy S, Reddy H, Muppaneni T, Downes C, Deng S, Life cycle assessment of biodiesel production from algal bio-crude oils extracted under subcritical water conditions, Bioresource Technology 2014;170:454-461. 
[29] Reddy H, Muppaneni T, Sun Y, Li Y, Ponnusamy S, Patil P, et al. Subcritical water extraction of lipids from wet algae for biodiesel production, Fuel 2014;133:73-81.

[30] Abu-Ghosh S, Fixler D, Dubinsky Z, Iluz D. Energy-input analysis of the life-cycle of microalgal cultivation systems and best scenario for oil-rich biomass production, Applied Energy 2015;154:1082-1088.

[31] Handler R M, Shonnard D R, Kalnes T N, Lupton F S. Life cycle assessment of algal biofuels: Influence of feedstock cultivation systems and conversion platforms, Algal Research 2014;4:105-115.

[32] Xu L, Brilman D W F, Withag J A M, Brem G, Kersten S. Assessment of a dry and a wet route for the production of biofuels from microalgae: Energy balance analysis, Bioresource Technology 2011;102(8):5113-5122.

[33] Geider R, La Roche J. Redfield revisited: variability of C:N:P in marine microalgae and its biochemical basis, European Journal of Phycology 2002;37(1):1-17.

[34] Al hattab M, Ghaly A, Hammouda A. Microalgae Harvesting Methods for Industrial Production of Biodiesel: Critical Review and Comparative Analysis, J Fundam Renewable Energy Appl 2015;5(2), doi: 10.4172/2090-4541.1000154.

[35] Sheng J, Vannela R, Rittmann B E. Disruption of Synechocystis PCC 6803 for lipid extraction, Water Science and Technology 2012;65(3):567-573.

[36] Halim R, Harun R, Danquah M K, Webley P A. Microalgal cell disruption for biofuel development, Applied Energy 2012;91:116121.

[37] Bhola V, Swalaha F, Ranjith Kumar R, Singh M, Bux F. Overview of the potential of microalgae for CO2 sequestration, Int. J. Environ. Sci. Technol. 2014;11:2103-2118.

[38] Yen H, Ho S, Chen C, Chang J, CO2, NOx and SOx removal from flue gas via microalgae cultivation: A critical review, Biotechnol. J. 2015;10:829-839.

[39] Lédé J, Authier O. Temperature and heating rate of solid particles undergoing a thermal decomposition. Which criteria for characterizing fast pyrolysis?, Journal of Analytical and Applied Pyrolysis 2015;113:1-14.

[40] Weschler M, Barr W, Harper W, Landis A. Process energy comparison for the production and harvesting of algal biomass as a biofuel feedstock, Bioresource Technology 2014;153:108-115.

[41] Collet P, Hélias A, Lardon L, Ras M, Goy R-A, Steyer J-P, Life-cycle assessment of microalgae culture coupled to biogas production, Bioresour Technol 2011;102(1):207-14.

[42] Lam M, Lee K. Microalgae biofuels: A critical review of issues, problems and the way forward, Biotechnology Advances 2012;30:673-690. 
[43] Jorquera O, Kiperstok A, Sales E A, Embiruçu M, Ghirardi M L. Comparative energy life-cycle analyses of microalgal biomass production in open ponds and photobioreactors, Bioresource Technology 2010;101(4):1406-1413.

[44] Ventura J, Yang B, Lee Y, Lee K, Jahng D. Life cycle analyses of CO2, energy, and cost for four different routes of microalgal bioenergy conversion”, Bioresource Technology 2013;137:302-310.

[45] Khoo H H, Sharratt P N, Das P, Balasubramanian R K, Naraharisetti P K, Shaik S. Life cycle energy and CO2 analysis of microalgaeto-biodiesel: Preliminary results and comparisons, Bioresource Technology 2011;102:5800-5807.

[46] Monari C, Righi S, Olsen S I. Greenhouse gas emissions and energy balance of biodiesel production from microalgae cultivated in photobioreactors in Denmark: a lifecycle modeling, Journal of Cleaner Production 2016;112:4084-4092.

[47] Lima Medeiros D, Sales E A, Kiperstok A. Energy production from microalgae biomass: carbon footprint and energy balance, Journal of Cleaner Production 2015;96:493-500.

[48] Frank E D, Han J, Palou-Rivera I, Elgowainy A, Wang M Q. Life-Cycle Analysis of Algal Lipid Fuels with the Greet Model, ANL/ESD/11-5. Available at https://greet.es.anl.gov/.

[49] Naraharisetti P K, Das P, Sharratt P N. Critical factors in energy generation from microalgae, Energy 2017;120(1):138-152.

[50] Günerken E, D'Hondt E, Eppink M H M, Garcia-Gonzalez L, Elst K, Wijffels R H, Cell disruption for microalgae biorefineries, Biotechnology Advances 2015;33(2):243-260.

[51] Sazdanoff N. Modeling and Simulation of the Algae to Biodiesel Fuel Cycle, Honors Undergraduate Thesis Submitted to The College of Engineering Honors Committee, The Ohio State University; 2006.

[52] Lardon L, Hélias A, Sialve B, Steyer J, Bernard O. Life-Cycle Assessment of Biodiesel Production from Microalgae, Environmental Science \& Technology 2009;43(17):6475-6481.

[53] Passell H, Dhaliwal H, Reno M, Wu B, Ben Amotz A, Ivry E, et al. Algae biodiesel life cycle assessment using current commercial data, Journal of Environmental Management 2013;129(15):103-111.

[54] Gnansounou E, Raman J, Life cycle assessment of algae biodiesel and its co-products, Applied Energy 2016;161:300-308.

[55] Razon L F, Tan R R, Net energy analysis of the production of biodiesel and biogas from the microalgae: Haematococcus pluvialis and Nannochloropsis, Applied Energy 2011;88(10):3507-3514.

[56] Yanfen L, Zehao H, Xiaoqian M. Energy analysis and environmental impacts of microalgal biodiesel in China, Energy Policy 2012;45:142-151.

[57] Pragya N, Pandey K K, Life cycle assessment of green diesel production from microalgae, Renewable Energy 2016;86:623-632.

[58] Röder M, Thornley P. Bioenergy as climate change mitigation option within a $2{ }^{\circ} \mathrm{C}$ target—uncertainties and temporal challenges 
of bioenergy systems, Energy, Sustainability and Society, 2016;6(6):1-7.

[59] Speirs J, McGlade C, Slade R, Uncertainty in the availability of natural resources: Fossil fuels, critical metals and biomass, Energy Policy 2015;87:654-664.

[60] McGlade C E, A review of the uncertainties in estimates of global oil resources, Energy 2012;47:262-270.

[61] Purkus A, Röder M, Gawel E, Thran D, Thornley P. Handling uncertainty in bioenergy policy design e A case study analysis of UK and German bioelectricity policy instruments, Biomass and Bioenergy 2015;79:64-79.

[62] Butler C, Demski C, Parkhill K, Pidgeon N, Spence A., Public values for energy futures: Framing, indeterminacy and policy making, Energy Policy 2015;87:665-672.

[63] Creutzig F, Popp A, Plevin R, Luderer G, Minx J, Edenhofer O, Reconciling top-down and bottom-up modelling on future bioenergy deployment, Nature Climate Change 2012;2:320-327.

[64] Spiegelhalter D J, Riesch H. Don't know, can't know: embracing deeper uncertainties when analysing risks, Philos Trans A Math Phys Eng Sci. 2011;369(1956):4730-50.

[65] Richardson J J, Spies K A, Rigdon S, York S, Lieu V, Nackley L, Uncertainty in biomass supply estimates: lessons from a Yakama Nation case study, Biomass \& Bioenergy 2011;35:3698-3707.

[66] Malca J, Freire F. Uncertainty Analysis in Biofuel Systems - An Application to the Life Cycle of Rapeseed Oil, Journal of Industrial Ecology 2010;14(2):322-334.

[67] Gonzalez-Salazar M A, Morini M, Pinelli M, Spina P R, Venturini M, Finkenrath M, et al. Methodology for Estimating Biomass Energy Potential and its Application to Colombia, Applied Energy 2014;136:781-796.

[68] Gonzalez-Salazar M A, Venturini M, Poganietz W R, Finkenrath M, Spina P R. Methodology for improving the reliability of biomass energy potential estimation, Biomass \& Bioenergy 2016;88:43-58.

[69] Laurens L M L, Dempster T A, Jones H D T, Wolfrum E J, Van Wychen S, McAllister J S P, et al. Algal Biomass Constituent Analysis: Method Uncertainties and Investigation of the Underlying Measuring Chemistries, Anal. Chem., 2012;84(4):1879-1887.

[70] Fagnart J-F, Germain M. Net energy ratio, EROEI and the macroeconomy, Structural Change and Economic Dynamics, 2016;37:121-126.

[71] Whitaker M, Heath G. Life Cycle Assessment of the Use of Jatropha Biodiesel in Indian Locomotives, National Renewable Energy Laboratory, Technical Report NREL/TP-6A2-44428, 2009. (Available electronically at http://www.osti.gov/bridge). 
[72] Fore S R, Porter P, Lazarus W. Net energy balance of small-scale on-farm biodiesel production from canola and soybean, Biomass \& Bioenergy 2011;35:2234-2244. 


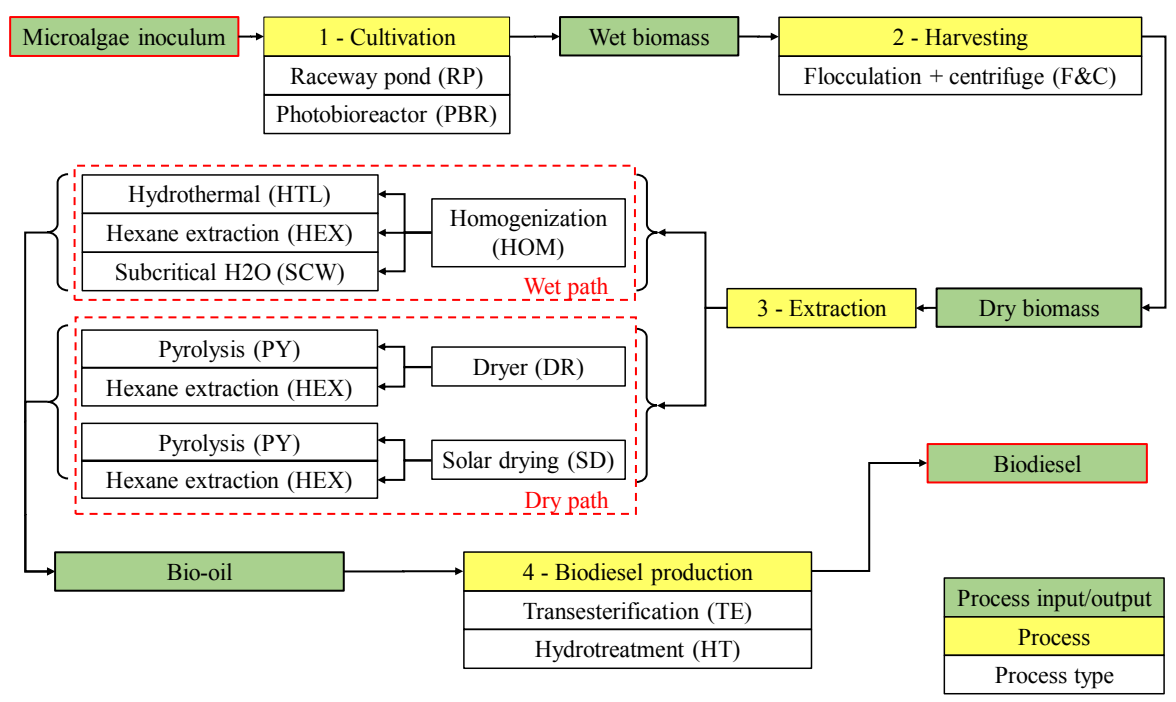

Figure 1 - Scheme of the complete chain for biodiesel production from algae 


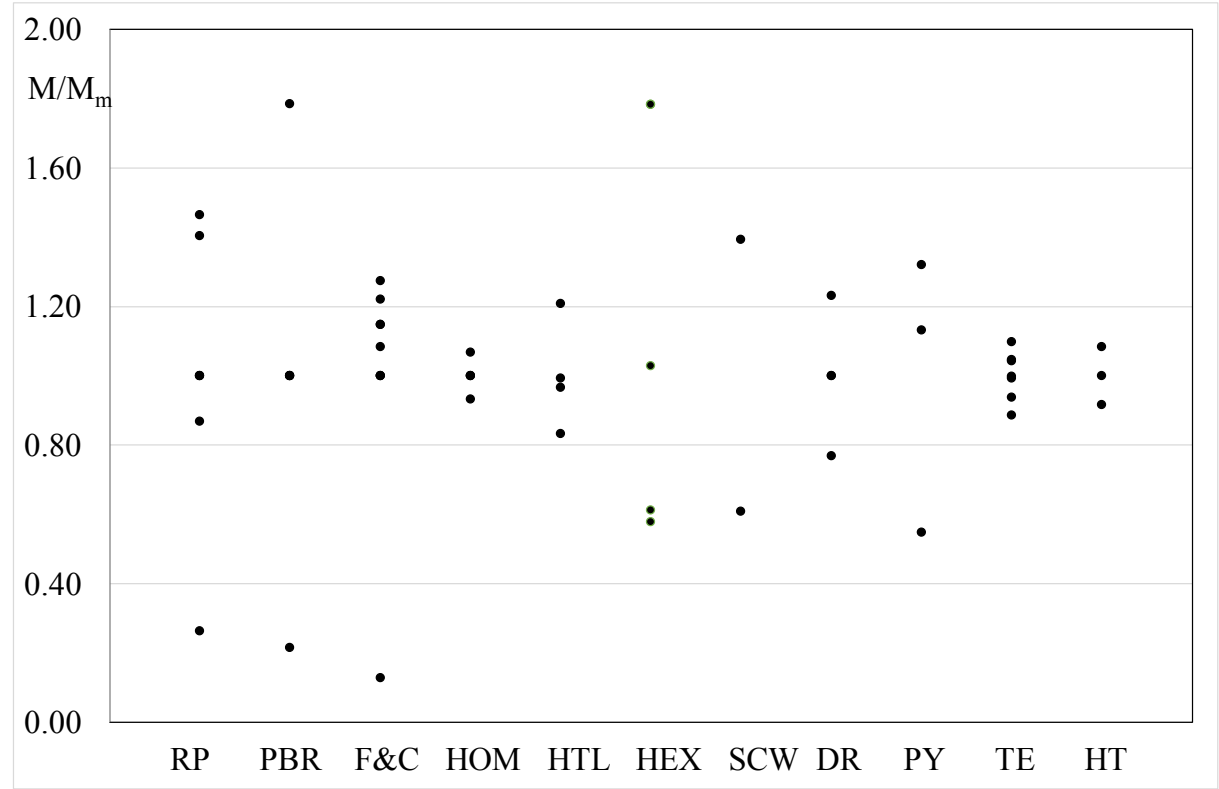

Figure 2 - Mass ratio reported in each source (see Table 2) divided by the mean value for each process (see Table 3 ) 


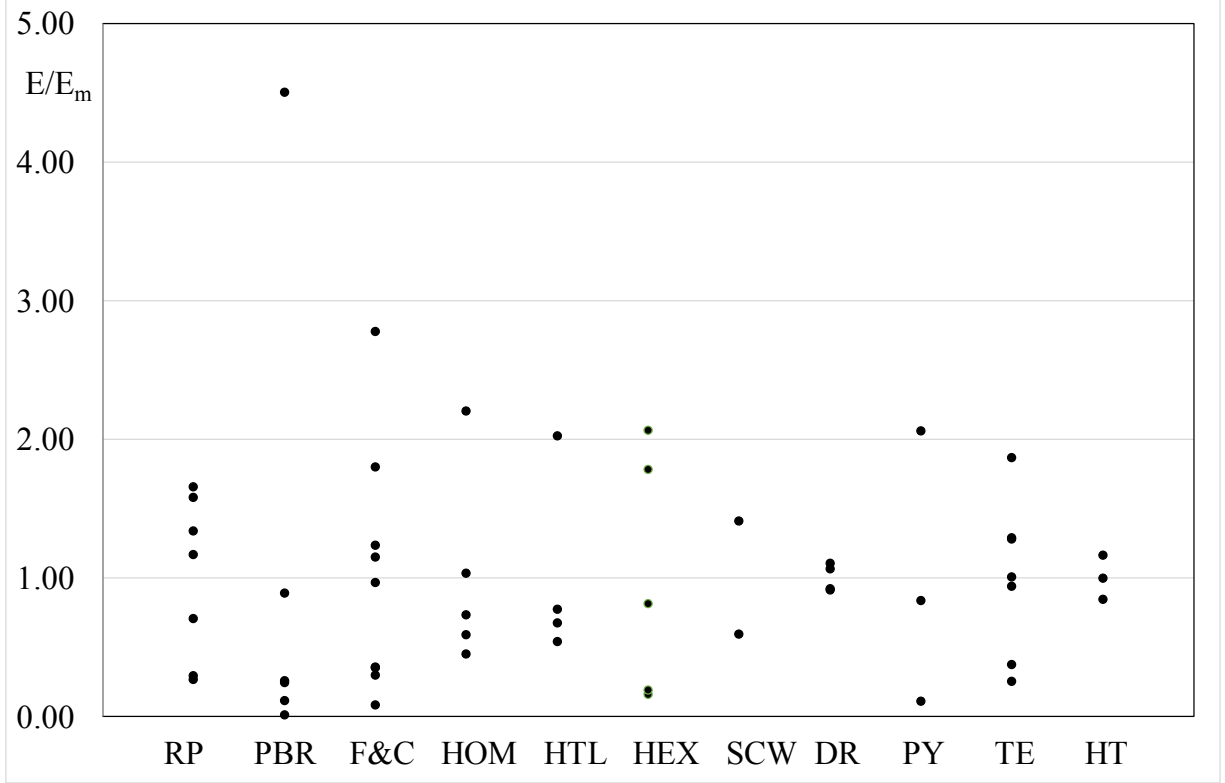

Figure 3 - Energy consumption reported in each source (see Table 2) divided by the mean value for each process (see Table 3 ) 


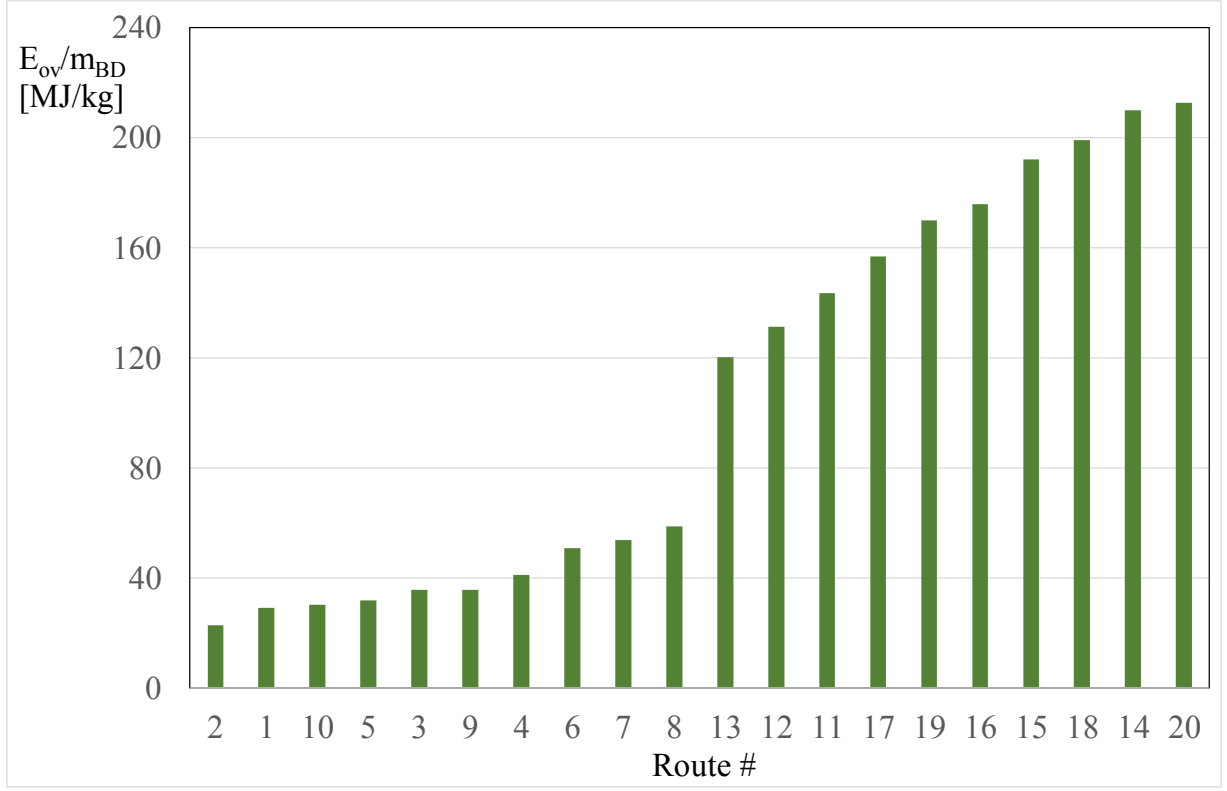

Figure 4 - Overall energy consumption for routes 1 through 20, ranked in ascending order of overall energy consumption per unit of mass of produced biodiesel $\left(E_{\mathrm{ov}} / m_{\mathrm{BD}}\right)$ 


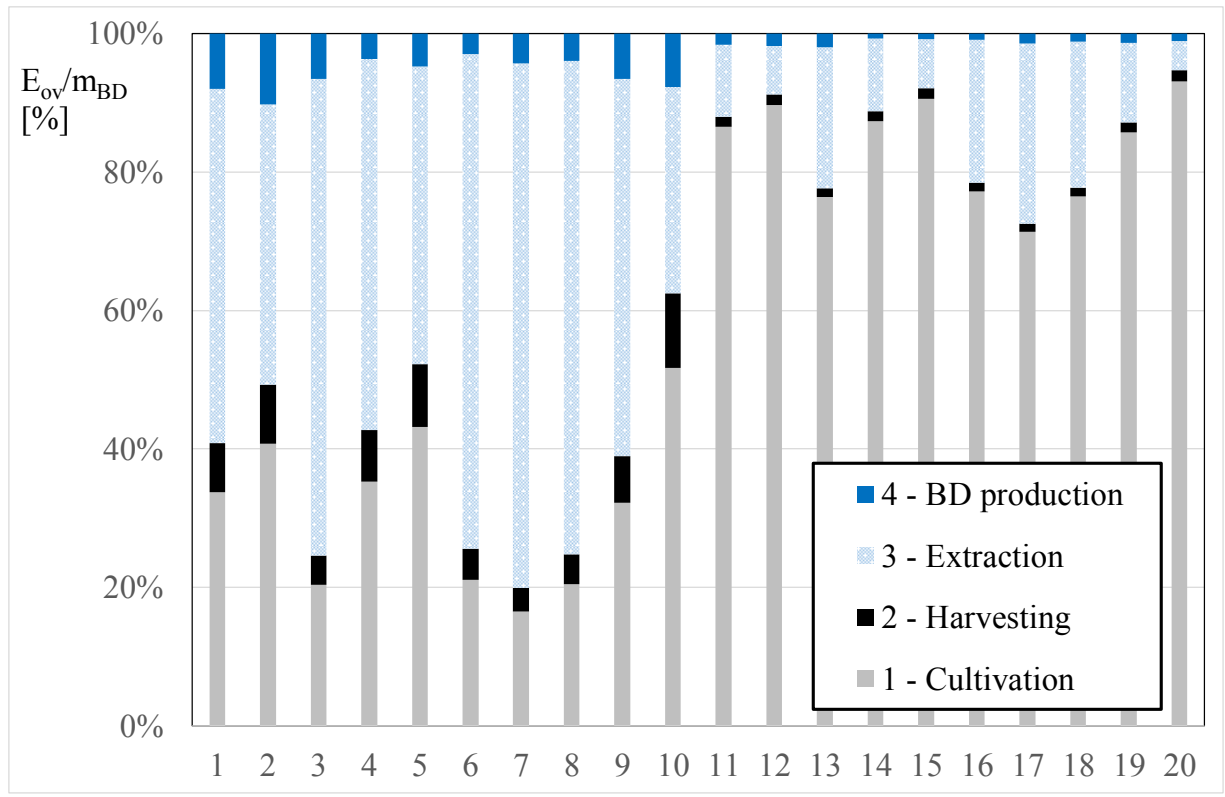

Figure 5 - Share of overall energy consumption by process for routes 1 through 20 


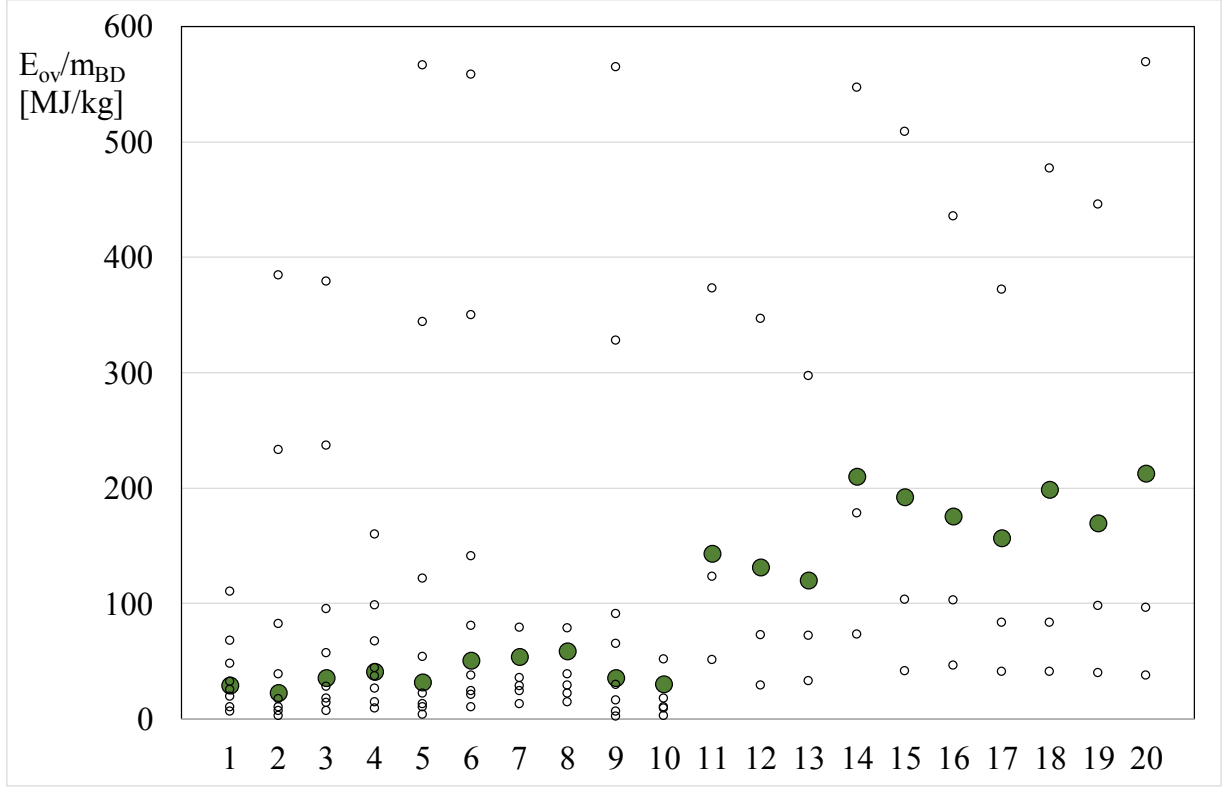

Figure 6 - Uncertainty on energy consumption estimation for the routes 1-20

(full circles: overall energy consumption estimated by using the energy consumption and mass ratio mean values; empty circles: overall energy consumption estimated by considering the uncertainty on the mean value of energy consumption and mass ratio) 


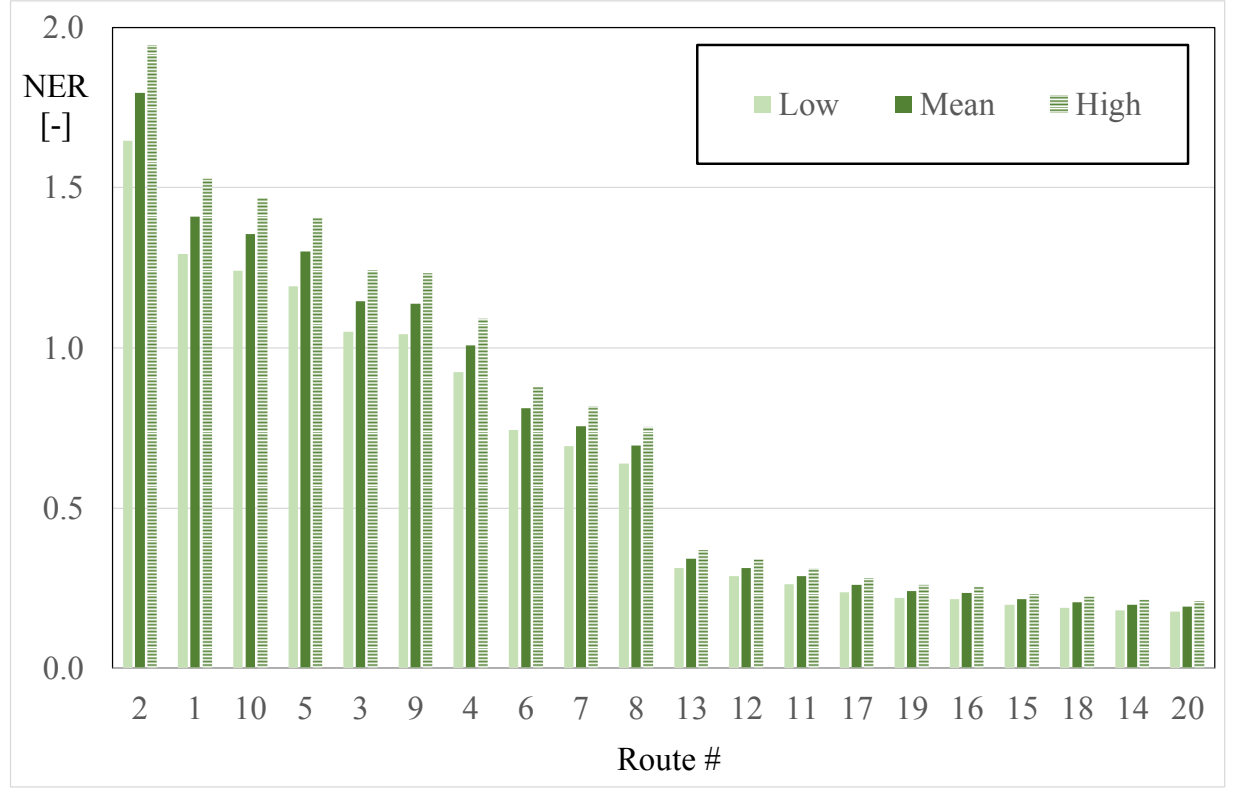

Figure 7 - Net Energy Ratio for the routes 1-20, ranked in descending order of NER values 
Table 1 - Considered technologies

\begin{tabular}{lll}
\hline \hline Step & Technology & Reference \\
\hline \hline \multirow{2}{*}{ Cultivation } & - raceway ponds (RP) & {$[16-18]$} \\
& - photobioreactors (PBR) & {$[19]$} \\
\hline \hline Harvesting & - flocculation and centrifuge (F\&C) & {$[20,21]$} \\
\hline \hline & - homogenization (HOM) & {$[22,23]$} \\
& - hydrothermal liquefaction (HTL) & {$[24-26]$} \\
Extraction & - hexane extraction (HEX) & {$[27]$} \\
& - H2O sub-critical extraction (SCW) & {$[28,29]$} \\
& - dryer (DR) & {$[21]$} \\
& - solar drying (SD) & {$[30]$} \\
& - pyrolysis (PY) & {$[26,31]$} \\
\hline \hline \multirow{2}{*}{ Biodiesel production } & - transesterification (TE) & {$[26,32]$} \\
& - hydrotreatment (HT) & {$[25]$} \\
\hline \hline
\end{tabular}


Table 2 - Data collection and homogenization (gray = original value reported in the source; red italic = assumption; bold = homogenized value)

\begin{tabular}{|c|c|c|c|c|c|c|c|c|c|c|}
\hline Process & Ref. & $\begin{array}{c}E_{1} / m_{\mathrm{BD}} \\
{[\mathrm{MJ} / \mathrm{kg}]}\end{array}$ & $M_{4}=\mathbf{m}_{\mathrm{BD}} / \mathbf{m}_{\mathrm{bo}}$ & $\begin{array}{c}E_{1} / m_{\text {bo }} \\
{[\mathrm{MJ} / \mathbf{k g}]}\end{array}$ & $M_{3}=\mathbf{m}_{\mathrm{bo}} / \mathbf{m}_{\mathbf{d b}}$ & $\begin{array}{c}E_{1} / m_{\mathrm{db}} \\
{[\mathrm{MJ} / \mathrm{kg}]}\end{array}$ & $M_{2}=\mathbf{m}_{\mathrm{db}} / \mathbf{m}_{\mathrm{wb}}$ & $\begin{array}{c}E_{1} / m_{\mathrm{wb}} \\
{[\mathrm{MJ} / \mathrm{kg}]}\end{array}$ & $M_{1}=\mathbf{m}_{\mathrm{wb}} / \mathbf{m}_{\mathrm{al}}$ & $\begin{array}{c}E / m_{\mathrm{al}} \\
{[\mathrm{MJ} / \mathbf{k g}]}\end{array}$ \\
\hline \multirow[t]{7}{*}{$\mathrm{RP}$} & {$[21]$} & & & & & 3.42 & 0.90 & 3.08 & 9.90 & 30.47 \\
\hline & {$[25]$} & & & & & 2.72 & 0.85 & 2.31 & 3.00 & 6.94 \\
\hline & {$[27]$} & 7.20 & 0.88 & 6.37 & 0.40 & 2.57 & 0.96 & 2.46 & 16.70 & 41.14 \\
\hline & {$[32]$} & & & & & 3.31 & 0.93 & 3.06 & 11.40 & 34.93 \\
\hline & {$[43]$} & & & & & & & 3.78 & 11.40 & 43.14 \\
\hline & {$[44]$} & & & & & 0.72 & 0.93 & 0.67 & 11.40 & 7.61 \\
\hline & {$[45]$} & & & & & 1.15 & 1.00 & 1.15 & 16.00 & 18.43 \\
\hline \multirow[t]{6}{*}{ PBR } & {$[27]$} & 199.50 & 0.88 & 176.55 & 0.40 & 71.25 & 1.02 & 72.84 & 83.00 & 6045.45 \\
\hline & {$[30]$} & & & & & 1.11 & 0.90 & 1.00 & 10.00 & 9.98 \\
\hline & {$[40]$} & & & & & & & 7.34 & 46.50 & 341.24 \\
\hline & {$[43]$} & & & & & & & 6.99 & 46.50 & 325.01 \\
\hline & {$[45]$} & & & & & 3.21 & 1.00 & 3.21 & 46.50 & 149.27 \\
\hline & {$[46]$} & 110.49 & 0.88 & 97.78 & 0.33 & 32.37 & 0.79 & 25.60 & 46.50 & 1190.30 \\
\hline Process & Ref. & $\begin{array}{c}E_{2} / m_{\mathrm{BD}} \\
{[\mathrm{MJ} / \mathrm{kg}]}\end{array}$ & $M_{4}=\mathbf{m}_{\mathrm{BD}} / \mathbf{m}_{\mathrm{bo}}$ & $\begin{array}{c}E_{2} / m_{\text {bo }} \\
{[\mathrm{MJ} / \mathrm{kg}]}\end{array}$ & $M_{3}=\mathbf{m}_{\mathrm{bo}} / \mathbf{m}_{\mathbf{d b}}$ & $\begin{array}{c}E_{2} / m_{\mathrm{db}} \\
{[\mathrm{MJ} / \mathbf{k g}]}\end{array}$ & $M_{2}=\mathbf{m}_{\mathrm{db}} / \mathbf{m}_{\mathrm{wb}}$ & $\begin{array}{c}E_{2} / m_{\mathrm{wb}} \\
{[\mathrm{MJ} / \mathrm{kg}]}\end{array}$ & & \\
\hline \multirow[t]{9}{*}{$\mathrm{F} \& \mathrm{C}$} & {$[21]$} & & & & 0.19 & 0.65 & 0.90 & 0.59 & & \\
\hline & {$[27]$} & 2.50 & 0.88 & 2.21 & 0.40 & 0.89 & 0.96 & 0.86 & & \\
\hline & {$[28]$} & & & & & & 0.78 & 0.17 & & \\
\hline & {$[30]$} & & & & & 0.51 & 0.90 & 0.46 & & \\
\hline & {$[32]$} & & & & & 0.17 & 0.85 & 0.14 & & \\
\hline & {$[40]$} & & & & & 1.32 & 1.00 & 1.32 & & \\
\hline & {$[44]$} & & & & & 0.70 & 0.78 & 0.55 & & \\
\hline & {$[45]$} & & & & & 0.38 & 0.10 & 0.04 & & \\
\hline & {$[47]$} & & & & & 0.22 & 0.78 & 0.17 & & \\
\hline Process & Ref. & $\begin{array}{c}E_{3} / m_{\mathrm{BD}} \\
{[\mathrm{MJ} / \mathrm{kg}]}\end{array}$ & $M_{4}=\mathbf{m}_{\mathrm{BD}} / \mathbf{m}_{\mathrm{bo}}$ & $\begin{array}{c}E_{3} / m_{\mathrm{bo}} \\
{[\mathrm{MJ} / \mathrm{kg}]}\end{array}$ & $M_{3}=\mathbf{m}_{\mathrm{bo}} / \mathbf{m}_{\mathrm{db}}$ & $\begin{array}{c}E_{3} / m_{\mathrm{db}} \\
{[\mathrm{MJ} / \mathrm{kg}]}\end{array}$ & & & & \\
\hline \multirow[t]{5}{*}{ HOM } & {$[27]$} & 1.70 & 0.88 & 1.50 & 0.84 & 1.27 & & & & \\
\hline & {$[48]$} & & & & 0.84 & 2.70 & & & & \\
\hline & {$[48]$} & & & & 0.90 & 0.72 & & & & \\
\hline & [49] & & & & 0.84 & 0.55 & & & & \\
\hline & {$[50]$} & & & & 0.79 & 0.90 & & & & \\
\hline HTL & {$[24]$} & 5.31 & 0.72 & 3.84 & 0.45 & 1.73 & & & & \\
\hline
\end{tabular}




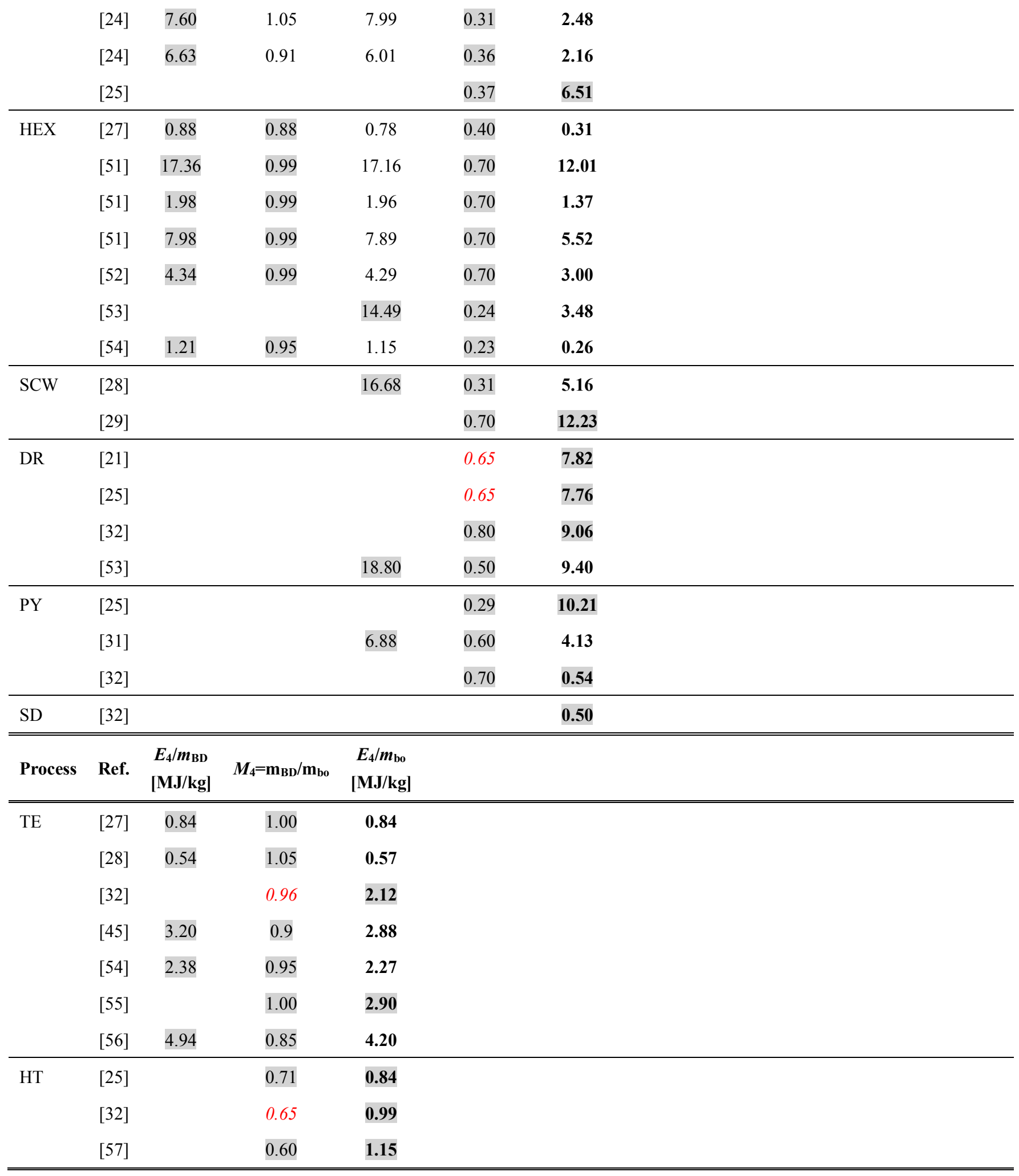


Table 3 - Homogenized values of mass ratio and energy consumption

\begin{tabular}{|c|c|c|c|c|}
\hline Process & Mean & Std. Dev. & Mean & Std. Dev. \\
\hline & \multicolumn{2}{|c|}{$M_{1}=\mathbf{m}_{\mathrm{wb}} / \mathbf{m}_{\mathrm{al}}$} & \multicolumn{2}{|c|}{$E_{1} / m_{\mathrm{al}}[\mathrm{MJ} / \mathrm{kg}]$} \\
\hline $\mathrm{RP}$ & 11.40 & 6.30 & 26.09 & 15.18 \\
\hline \multirow[t]{2}{*}{ PBR } & 46.50 & 51.62 & 1343.54 & 2340.01 \\
\hline & \multicolumn{2}{|c|}{$M_{2}=\mathbf{m}_{\mathrm{db}} / \mathbf{m}_{\mathrm{wb}}$} & \multicolumn{2}{|c|}{$E_{2} / m_{\mathrm{wb}}[\mathrm{MJ} / \mathrm{kg}]$} \\
\hline \multirow[t]{2}{*}{$\mathrm{F} \& \mathrm{C}$} & 0.78 & 0.27 & 0.48 & 0.41 \\
\hline & \multicolumn{2}{|c|}{$M_{3}=\mathbf{m}_{\mathrm{bo}} / \mathbf{m}_{\mathbf{d b}}$} & \multicolumn{2}{|c|}{$E_{3} / m_{\mathrm{db}}[\mathrm{MJ} / \mathrm{kg}]$} \\
\hline HOM & 0.84 & 0.04 & 1.23 & 0.86 \\
\hline HTL & 0.37 & 0.006 & 3.22 & 2.21 \\
\hline HEX & 0.39 & 0.22 & 1.69 & 1.50 \\
\hline SCW & 0.50 & 0.28 & 8.69 & 5.00 \\
\hline DR & 0.65 & 0.12 & 8.51 & 0.84 \\
\hline PY & 0.53 & 0.21 & 4.96 & 4.89 \\
\hline \multirow[t]{2}{*}{ SD } & 0.50 & 0 & 0 & 0 \\
\hline & \multicolumn{2}{|c|}{$M_{4}=\mathbf{m}_{\mathrm{BD}} / \mathbf{m}_{\mathrm{bo}}$} & \multicolumn{2}{|c|}{$E_{4} / m_{\text {bo }}[\mathrm{MJ} / \mathrm{kg}]$} \\
\hline $\mathrm{TE}$ & 0.96 & 0.07 & 2.25 & 1.26 \\
\hline HT & 0.65 & 0.05 & 0.99 & 0.16 \\
\hline
\end{tabular}


Table 4 - Routes for biodiesel production from algae

\begin{tabular}{|c|c|}
\hline \# & Route \\
\hline 1 & $\mathrm{RP}+\mathrm{F} \& \mathrm{C}+(\mathrm{HOM}+\mathrm{HTL})+\mathrm{TE}$ \\
\hline 2 & $\mathrm{RP}+\mathrm{F} \& \mathrm{C}+(\mathrm{HOM}+\mathrm{HEX})+\mathrm{TE}$ \\
\hline 3 & $\mathrm{RP}+\mathrm{F} \& \mathrm{C}+(\mathrm{HOM}+\mathrm{SCW})+\mathrm{TE}$ \\
\hline 4 & $\mathrm{RP}+\mathrm{F} \& \mathrm{C}+(\mathrm{HOM}+\mathrm{HTL})+\mathrm{HT}$ \\
\hline 5 & $\mathrm{RP}+\mathrm{F} \& \mathrm{C}+(\mathrm{HOM}+\mathrm{HEX})+\mathrm{HT}$ \\
\hline 6 & $\mathrm{RP}+\mathrm{F} \& \mathrm{C}+(\mathrm{HOM}+\mathrm{SCW})+\mathrm{HT}$ \\
\hline 7 & $\mathrm{RP}+\mathrm{F} \& \mathrm{C}+(\mathrm{DR}+\mathrm{PY})+\mathrm{TE}$ \\
\hline 8 & $\mathrm{RP}+\mathrm{F} \& \mathrm{C}+(\mathrm{DR}+\mathrm{HEX})+\mathrm{TE}$ \\
\hline 9 & $\mathrm{RP}+\mathrm{F} \& \mathrm{C}+(\mathrm{SD}+\mathrm{PY})+\mathrm{TE}$ \\
\hline 10 & $\mathrm{RP}+\mathrm{F} \& \mathrm{C}+(\mathrm{SD}+\mathrm{HEX})+\mathrm{TE}$ \\
\hline 11 & $\mathrm{PBR}+\mathrm{F} \& \mathrm{C}+(\mathrm{HOM}+\mathrm{HTL})+\mathrm{TE}$ \\
\hline 12 & $\mathrm{PBR}+\mathrm{F} \& \mathrm{C}+(\mathrm{HOM}+\mathrm{HEX})+\mathrm{TE}$ \\
\hline 13 & $\mathrm{PBR}+\mathrm{F} \& \mathrm{C}+(\mathrm{HOM}+\mathrm{SCW})+\mathrm{TE}$ \\
\hline 14 & $\mathrm{PBR}+\mathrm{F} \& \mathrm{C}+(\mathrm{HOM}+\mathrm{HTL})+\mathrm{HT}$ \\
\hline 15 & $\mathrm{PBR}+\mathrm{F} \& \mathrm{C}+(\mathrm{HOM}+\mathrm{HEX})+\mathrm{HT}$ \\
\hline 16 & $\mathrm{PBR}+\mathrm{F} \& \mathrm{C}+(\mathrm{HOM}+\mathrm{SCW})+\mathrm{HT}$ \\
\hline 17 & $\mathrm{PBR}+\mathrm{F} \& \mathrm{C}+(\mathrm{DR}+\mathrm{PY})+\mathrm{TE}$ \\
\hline 18 & $\mathrm{PBR}+\mathrm{F} \& \mathrm{C}+(\mathrm{DR}+\mathrm{HEX})+\mathrm{TE}$ \\
\hline 19 & $\mathrm{PBR}+\mathrm{F} \& \mathrm{C}+(\mathrm{SD}+\mathrm{PY})+\mathrm{TE}$ \\
\hline 20 & $\mathrm{PBR}+\mathrm{F} \& \mathrm{C}+(\mathrm{SD}+\mathrm{HEX})+\mathrm{TE}$ \\
\hline
\end{tabular}


Table 5 - Cases for evaluating the influence of uncertainty on overall energy consumption

\begin{tabular}{lll}
\hline \hline Energy & Mass ratio & Symbol in Fig. 6 \\
\hline \hline$E_{\mathrm{m}}$ & $M_{\mathrm{m}}$ & full circle \\
\hline \hline$E_{\mathrm{m}}+E_{\mathrm{sd}}$ & $M_{\mathrm{m}}$ & \\
$E_{\mathrm{m}}-E_{\mathrm{sd}}$ & $M_{\mathrm{m}}$ & \\
$E_{\mathrm{m}}$ & $M_{\mathrm{m}}+M_{\mathrm{sd}}$ & \\
$E_{\mathrm{m}}$ & $M_{\mathrm{m}}-M_{\mathrm{sd}}$ & empty circle \\
$E_{\mathrm{m}}+E_{\mathrm{sd}}$ & $M_{\mathrm{m}}+M_{\mathrm{sd}}$ & \\
$E_{\mathrm{m}}+E_{\mathrm{sd}}$ & $M_{\mathrm{m}}-M_{\mathrm{sd}}$ & \\
$E_{\mathrm{m}}-E_{\mathrm{sd}}$ & $M_{\mathrm{m}}+M_{\mathrm{sd}}$ & \\
$E_{\mathrm{m}}-E_{\mathrm{sd}}$ & $M_{\mathrm{m}}-M_{\mathrm{sd}}$ & \\
\hline \hline
\end{tabular}


Table 6 - Biodiesel LHV

\begin{tabular}{ll}
\hline \hline Value $[\mathbf{M J} / \mathbf{k g}]$ & Ref. \\
\hline \hline 37.17 & {$[16]$} \\
43.00 & {$[31]$} \\
38.30 & {$[32]$} \\
44.00 & {$[57]$} \\
\hline 40.62 & Mean value \\
3.38 & Standard deviation \\
\hline \hline
\end{tabular}




\title{
HARMONIZED AND SYSTEMATIC ASSESSMENT OF MICROALGAE ENERGY POTENTIAL FOR BIODIESEL PRODUCTION
}

\author{
Francesco Arcigni ${ }^{1}$, Riccardo Friso ${ }^{1}$, Maurizio Collu², Mauro Venturini ${ }^{1}$ * \\ ${ }^{1}$ Dipartimento di Ingegneria, Università degli Studi di Ferrara, Via Giuseppe Saragat, 1, 44122 - Ferrara (Italy) \\ ${ }^{2}$ Department of Naval Architecture, Ocean \& Marine Engineering, University of Strathclyde, 100 Montrose Street, \\ Glasgow G4 OLZ, United Kingdom \\ ${ }^{*}$ Corresponding author: Mauro Venturini \\ Dipartimento di Ingegneria - Università degli Studi di Ferrara \\ Via Giuseppe Saragat, 1, 44122 - Ferrara (Italy) \\ Phone\#: +390532 974878 \\ email address: mauro.venturini@unife.it
}


MANUSCRIPT NO.: RSER-D-18-00453

\section{Highlights}

- Quantitative, systematic and harmonized assessment of microalgae energy potential

- A step-by-step analysis and overall estimation of energy consumption is given

- A substantial uncertainty on the data in literature has been identified

- The energy consumption uncertainty is quantified and critically discussed

- Derivation of the Net Energy Ratio (NER) for each combination of technologies 